\title{
Cricket: notching up runs for food and alcohol companies?
}

\author{
Jill Sherriff ${ }^{1}$, Denise Griffiths ${ }^{1}$ and Mike Daube ${ }^{2}$ \\ ${ }^{1}$ School of Public Health, Curtin Health Innovative Research Institute, Curtin University \\ of Technology, Western Australia \\ ${ }^{2}$ Public Health Advocacy Institute of WA, Curtin University of Technology, Western \\ Australia
}

\section{Abstract}

Objective: To analyse sports sponsorship by food and alcohol companies by quantifying the proportion of time that the main sponsor's logo was seen during each of three cricket telecasts, the extent of paid advertising during the telecast and the contribution by the main sponsor to this, and to describe the associated ground advertising.

Methods: DVD recordings of the three telecasts were analysed for visibility of the main sponsor's logo during actual playing time and for each sponsor's proportion of the advertising time during the breaks in telecast.

Results: The main sponsor's logo was visible on a range of equipment and clothing which resulted in it being clearly identifiable from 44 to $74 \%$ of the game time. The proportion of paid advertising time in these three telecasts varied from 3 to $20 \%$, reflecting the difference in advertising content of paid television versus free-to-air.

Implications: While television food advertising to children is under review, sporting telecasts also reach children and until recently, have avoided scrutiny. This content analysis of three recent cricket telecasts reveals an unacceptable level of exposure to food and alcohol marketing, particularly in the form of the main sponsors' logo. Sponsorship is not covered by the voluntary codes of practice which address some forms of advertising. A new system of regulation is required to reduce this unacceptable level of exposure. 


\section{Introduction}

Food and alcohol marketing in Australia assumes many forms including television and internet advertisements, sponsorship, competitions and point-of-sale promotion. Swinburn et al. ${ }^{1}$ identified the marketing of food as a macroenvironmental sector of our obesogenic environment as is evidenced by the bias towards the advertising of unhealthy foods. ${ }^{2}$ Furthermore, studies suggest that the marketing of alcohol stimulates consumption of alcohol by both adults and teenagers rather than simply influencing the choice of beverage or brand. ${ }^{3}$

Promotional activity by the food and beverage industry is acknowledged as having an impact on children ${ }^{4}$, and it has been demonstrated that increases in television viewing by teenagers predict increases in energy intake and that this is mediated by increasing consumption of energy-dense foods commonly advertised on television. ${ }^{5}$ In Australia, the commercial promotion of food and beverages high in fat, sugar and salt to children is under attack by advocacy groups (Coalition on Food Advertising to Children ${ }^{6}$, Australian Medical Association ${ }^{7}$ ) and research has been conducted on its extent and impact. ${ }^{2}$ In contrast, marketing through sports sponsorship reaches children/adolescents as part of its wider audience but had not attracted the same level of public commentary until this year when it became the subject of parliamentary debate in Australia ${ }^{8}$. Nonetheless comments on the incongruity of certain sponsorships have been expressed, particularly in the medical literature ${ }^{9,10}$.

Lardinoit \& Quester, in their analysis of sponsorship of basketball in Europe ${ }^{11}$, note that there is broad agreement with Meenaghan's view that “commercial sponsorship involves an investment in cash or kind in an activity, person or idea for the purpose of exploiting the commercial potential associated with this activity.” There are many goals of sponsorship, including: enhancing the corporate image, adding value to the organizational communications, increasing goodwill among opinion formers or promoting brand awareness. $^{12}$ Until the late 1980s tobacco companies were a major sports sponsor in Australia. After tobacco advertising and promotion including sport sponsorship was progressively banned in Australia, sports were sponsored by health promotion 
organizations in Victoria, South Australia, the Australian Capital Territory and Western Australia. ${ }^{13}$ The initial impetus for the involvement of health promotion organizations in sponsorship was to provide replacement funding for sports and arts organizations that had been reliant on the tobacco industry. ${ }^{13}$ Thus health promotion foundations were formed, for example, the Victorian Health Promotion Foundation (VicHealth) and the Western Australian Health Promotion Foundation (Healthway), and funded by an increase in tobacco tax and a levy on the wholesale distribution of tobacco products, respectively ${ }^{13}$. Sponsorship of major Australian professional and community sporting organizations by food and alcohol companies gained momentum and is now a widespread practice. ${ }^{14,15,16}$ Sponsorship is the world's fastest growing form of marketing, ${ }^{12}$ with drivers for its proliferation including the cost-effectiveness of sports sponsorship for corporations, ${ }^{17}$ its suitability as a global communications medium, ${ }^{9,18}$ the lack of international regulation ${ }^{9}$, and the size of the audience that can be captured. ${ }^{9}$

The International Obesity Taskforce's Sydney Principles are guiding principles for achieving a substantial level of protection for children against the commercial promotion of foods and beverages. ${ }^{19}$ Principle number 4 is to take a wide definition of commercial promotions in relation to regulations, and specifies sponsorship in the list of examples. There is no regulation of sports sponsorship by food and alcohol companies as it is not covered by the voluntary codes of practice addressing some forms of direct advertising. A study of internet sports sponsorship in New Zealand revealed a higher proportion of unhealthy messages (those that pose risks to health, for example, food high in fat and sugar, gambling, alcohol) than healthy ones (favouring improved nutrition), which led the authors to suggest that some level of regulation needed to be considered. ${ }^{20}$

Commercial sponsorship has been categorised as field or on-site sponsorship (placement of logos) and broadcast or television sponsorship (association by name). ${ }^{21}$ However, sponsorship of sport by food and alcohol companies often combines both of these categories and is accompanied by television advertising. Thus several marketing tools are skillfully employed - not only personal endorsements by sporting heroes during advertising breaks in the game, but also the naming of series, advertising at sports stadia, 
promotional clothing for players and fans, logo exposure throughout the game and linkage with television product advertising campaigns during and around games. Such exhaustive attempts to build brand recognition (branding), a strategy designed to establish recognition and positive associations with a company name or product, ${ }^{22}$ illustrate the fact that sports telecasts are part of the "surrender of culture and education to marketing" which was examined by Naomi Klein in her book No logo. ${ }^{23}$

Meenaghan, one of the early investigators of the impact of the combination of direct and indirect marketing on consumers, proposed that the effects of sponsorship differ from those of advertising and other promotional approaches ${ }^{21}$. He argued that telecast sports sponsorship engages the consumer differently by bestowing benefit on activities that are highly valued by the audience ${ }^{21}$. The juxtaposition of a healthy activity (sport) with products whose over-use poses risk to health (alcohol \& energy-dense food) is an attempt to improve the image of the companies, and this goodwill further distinguishes sponsorship from advertising.

Analysis of the extent of marketing associated with food and alcohol within telecasts of sporting events is a neglected area of research. As a step in this direction, we quantified the proportion of time that the main sponsor's logo was seen during each of three cricket telecasts in January-February, 2008. There were two main sponsors involved in our study, both having naming rights to at least one of the series represented by the telecasts analysed. In addition we investigated the extent of paid advertisement breaks during the telecast, the contribution by the sponsor to this and the nature of any associated ground advertising.

\section{Methods}

We undertook a content analysis of the telecasts of two new forms of cricket in Australia. Kentucky Fried Chicken (KFC) and XXXX Gold were the main sponsors of the Twenty20 and Beach Cricket, respectively. Television telecasts of two $K F C^{\circledR}$ Twenty20 Cricket matches and one from the $X X X X^{T M} G O L D$ Beach Cricket competition were 
recorded (Table 1). These forms of cricket were of interest because they were both new to Australia (introduced in the summer of 2007) and are associated with an unprecedented level of marketing by the main sponsor in each case. The $K F C^{\circledR}$ Twenty20 International game between Australia and India on Feb 12008 was the last of two international games in the 2007/2008 season ${ }^{14}$ and attracted an estimated audience from Sydney, Melbourne, Brisbane, Adelaide and Perth of 2,077,000. ${ }^{24}$ The $K F C^{\circledR}$ Twenty20 Big Bash was the final and $16^{\text {th }}$ game of the national competition, and the $5^{\text {th }}$ game in the series to be telecast. ${ }^{25}$ The $X X X X^{T M}$ GOLD Beach Cricket game analysed was the final of the Tri-Nations series which featured games in Perth, Adelaide, Sydney (two games) and the Gold Coast (one game and the final) ${ }^{26}$. By definition, this last series was not played on cricket grounds.

Content analysis of these recordings was done by one of the authors (DG) and commenced with the start of play (warm-up and pre-game interviews were excluded) and ceased at the end of the game with the fall of the final wicket. The telecast analysis was divided into actual playing time (game time) plus advertisement breaks. The $K F C^{\circledR}$ Twenty20 International telecast included the half-time entertainment (interviews and game statistics). All data were DVD-recorded which allows for precise timing and instantaneous freeze-framing when monitoring. The definition of what constituted the image being monitored was discussed by the authors and agreed to be from the time when the main sponsor's logo (not just the colour) was instantly recognisable until it was no longer clear. Clear images were recorded to the nearest second. Only visual data were analysed, that is, spoken references were not considered.

Each telecast was analysed for the following:

- main sponsor's logo screen time during the game - types (wickets, playing field, players' clothing, fence signage), frequency and duration

- paid advertisement breaks - type (main sponsor or other), frequency and duration

- venue advertisements for foods/beverages - type and product.

Table 1 about here 


\section{Results}

For each game the main sponsor's logo was displayed on the following:

KFC $^{\circledR}$ Twenty20 Big Bash

- $\quad$ players' uniforms (front, back and sleeve of shirt, cap, pants)

- $\quad$ umpires’ uniform (shirt)

- playing surface

- $\quad$ stumps

- $\quad$ telecast graphics (statistic tables, player line-up tables etc)

- $\quad$ fence signage behind the wickets

$X X X X^{T M}$ GOLD Beach Cricket Tri-nations 2008

- $\quad$ players' uniforms (back and sleeve of shirt, cap)

- $\quad$ umpires' and boundary officials’ uniforms (shirt)

- $\quad$ stumps

- $\quad$ along the wicket

- players’ cricket bats

- $\quad$ telecast graphics (replay)

- $\quad$ fence signage (many)

- $\quad$ free standing flags and signs (including the boundary rope)

- $\quad$ promotional hats worn by spectators

- cheer girls

- $\quad$ scoreboard logo

\section{$K_{F C}{ }^{\circledR}$ Twenty20 International}

- $\quad$ players' uniforms (front, back and sleeve of shirt, cap, pants)

- $\quad$ umpires' uniforms (shirt)

- playing surface

- $\quad$ stumps

- $\quad$ telecast graphics (statistic tables)

- $\quad$ advertisement crawl across the screen

- $\quad$ fence signage behind the wickets 
- balloon man at the ground

- crowd wearing shirts and hats (approximately 150 spectators)

The time the sponsor's logo was identifiable in the three games ranged from 44 to $74 \%$ of the game time, thus a viewer could clearly identify the logo for about half the time. The longest continuous exposure (involving several places but measured as at least one image all the time) to the sponsor's logo was $75 \mathrm{sec}$ (Table 2).

Table 2 about here

There was considerable variation in the paid advertising time, ranging from $3 \%$ to $20 \%$ of the telecast time (Table 3). These advertisements were analysed as being linked those for the main sponsor or any other type of advertisement. This range reflects the difference in advertising content of paid television (3\%) versus free-to-air (16 and 20\%). One sponsor paid for no or few advertisements whereas the other used $26 \%$ of the paid advertising time.

The venues hosting the Twenty20 games displayed a variety of other food and beverage advertisements which are permanent advertisements not specific to each game, and the Melbourne Cricket Ground telecast included a Solo ${ }^{\circledR}$ advertisement across the screen.

The permanent advertisements were:

Western Australia Cricket Association Ground

- VB fence sign

- VB logo on Victorian Bushrangers playing shirt.

- Wolf Blass fence sign

- Coca-Cola ${ }^{\circledR}$ fence signs and free standing signage

- Carton Midstrength scoreboard

- Four'N Twenty free standing sign

- "burger bar" free standing sign

- Johnnie Walker ${ }^{\circledR}$ fence sign

Melbourne Cricket Ground

- Johnnie Walker ${ }^{\circledR}$

- VB (including side screen)

- Wolf Blass

- Coca-Cola ${ }^{\circledR}$

- MILO 
- Powerade $^{\circledR}$

- Solo ${ }^{\circledR}$ as an advert runner across the screen

In contrast, the beach cricket venue had no other food or beverage advertising. 


\section{Discussion}

To our knowledge this is the first quantification of exposure to the primary sponsor's logo during sponsored telecasts of sporting events. Twenty20 and Beach Cricket were introduced to Australia in 2007 and are characterised by an unprecedented level of marketing by a primary sponsor. The $K F C^{\circledR}$ Twenty20 International game was representative in that it was one of two from this series played in Australia in the summer of 2007/2008. It attracted the 3rd largest audience for metropolitan (Sydney, Melbourne, Brisbane, Adelaide and Perth) free-to-air television in the week 27 Jan to 2 Feb, 2008, coming behind the 2008 Australian Open Men's Final and Men’s Final Presentation. ${ }^{24}$ The other games were both finals for their respective series, not all of which were televised. This content analysis has revealed that the logo of each main sponsor was clearly visible for $44-74 \%$ of the match time, with uninterrupted stretches of exposure up to $75 \mathrm{sec}$. These are conservative estimates as only footage where the sponsors' logos were clearly visible was included in the analysis. The alcohol sponsor, whose logo was visible for a high proportion of game time (74\%), also paid for about a quarter of the advertising during breaks in the beach-cricket game. The two games that were telecast from cricket grounds incorporated additional food and beverage advertising during the game time, many of which related to nutrient-dense food and alcohol.

Examination over the last decade of the rise and influence of the phenomenon of branding has been led by journalists, in particular Naomi Klein and Eric Schlosser ${ }^{27}$. In No Space, the first section of her book, Klein ${ }^{23}$ argues that the corporate world is obsessed with brand identity and that branding has consumed virtually all public and private space. Klein further asserts that corporate sponsorship has become intrusive to the point where the logo is the main attraction. Bradshaw et $\mathrm{al}^{27}$ have explored No Space in their study of the manner in which the music culture has been "colonized by branding", 25 including the portrayal of musicians as opinion leaders. While the branding of the sports culture doesn't appear to have been examined to the same degree in the marketing literature, the telecasts analysed in this study revealed both of these elements; branding resulted in not only the sponsors' logos being visible for a large proportion of the playing time and thus intruding on the game, but the sportsmen themselves, via the 
advertisements, portrayed the food and alcohol consumption behaviours and associated positive experiences that the marketers wished to convey. The impact of food branding, seen here not just in the form of the KFC logo but also during the advertisements and via the permanent ground advertising, on overweight children versus non-overweight children is being investigated, for example, a pilot study has shown that overweight children may be more sensitive than non-overweight children to the impact of branded foods on intake. ${ }^{28}$

These novel forms of cricket are not alone in attracting alcohol and food sponsorship every major Australian Football League, National Rugby League and cricket team (state and national, test and one-day) has either alcohol and/or energy-dense food sponsorship, and most have both. ${ }^{14,15,16}$ The extent of sponsorship of sport is of concern because of the style of persuasion achieved by this form of marketing. It is argued by Meenagham ${ }^{21}$ that consumers are less able to resist and are more open to the indirect or covert persuasion which characterizes sponsorship, and Lardinoit and Quester maintain that sponsorship is more accepted by the public than advertising. ${ }^{11}$ Sponsorship of sporting telecasts is not likely to decrease because new technologies will increasingly provide the option of avoiding normal advertising, and sponsorship bypasses this hurdle by merging into the programming. ${ }^{29}$

While the regulation of TV food advertising to children is under review in Australia, ${ }^{30}$ other forms of marketing such as sports sponsorships are not subject to such reviews and are not covered by the voluntary codes of practice which address some forms of advertising. ${ }^{31}$ The current review ${ }^{30}$ is of television advertising during programs that appeal to children up to 14 years and does not consider programs such as televised sponsored sport that attract children, adolescents and adults. Thus sports sponsorship through telecasts is able to saturate family viewing time without any form of regulation, whether enforced or self-imposed. The marketing of energy-dense food to an audience which includes children and adolescents contributes to their obesogenic environment ${ }^{1}$. These data suggest that even if a tighter regulation of television advertising standards to 
children is achieved, children will be far from free of such influences on their eating patterns.

In a commentary on the 2006 World Cup, sport sponsorship, and health ${ }^{9}$, Collin and MacKenzie called for a broader application of the ethical basis for regulation and voluntary codes, namely the belief that sport should not be used to promote unhealthy behaviour. The food and alcohol industries' frequent retreat from this stance has been made possible by arguments about what constitutes unhealthy behaviour. The recent review of nutrient profiling by Lobstein and Davies ${ }^{32}$ should help dispense with the mantra of the last two decades, namely "there is no such thing as good and bad foods, only good and bad diets”32 and assist in the introduction of a widely accepted notion of unhealthy food.

Alcohol is a defining element of Australian social life for both adults and adolescents. In a 2005 survey, 50.6\% of 16-17 year olds reporting drinking alcohol in the previous week and $19.5 \%$ of these current $16-17$ year old drinkers drank quantities which posed health risks. ${ }^{33}$ Maher et al $^{20}$ noted that in their survey of internet sponsorship there were significantly more alcohol sponsors for rugby compared to all the other sports combined, suggesting that some sports are targeted by alcohol sponsors.

The marketing of alcohol promotes highly desirable aspects of life to adolescents and young adults, including desirable personality attributes in social settings. ${ }^{34}$ While Australia relies on a system of self-regulation of marketing, research indicates that the industry regularly flouts its own rules. ${ }^{35}$ Furthermore, the National Committee for the Review of Alcohol Advertising did not recommend that sponsorship be included in the Alcoholic Beverage Advertising Code's definition of an advertisement. ${ }^{36}$ Even if the current code for alcoholic beverage advertising covered sports sponsorship, the scheme relies on a complaint to trigger an assessment, a process which removes the responsibility from the marketer. 
Australians value their freedom of speech and there may be understandable reluctance to regulate, but only regulation can reduce the association of sport with what has become saturation marketing of energy-dense food and alcohol. Even with regulation, Collin and MacKenzie $^{9}$ point to the example of the Federation Internationale de Football Association's retreat from the standards which led to its WHO award in 2002 for the tournament's exemplary tobacco-free policy. With the current level of harm that is evident from the overconsumption of energy-dense food and alcohol, a more effective and far-reaching system of regulating the food and alcohol marketing to which Australian children and adolescents are relentlessly subjected is long overdue.

\section{Conclusion}

Viewing of sporting telecasts sponsored by food and alcohol companies has reached saturation level with $44-74 \%$ of the game time of three recent cricket events resulting in clear exposure to the sponsors' logos, and the uninterrupted screening of a logo lasting up to 75 seconds. Additional food and beverage marketing was incorporated through television advertisements in free-to-air telecasts and ground advertising when the venue was a cricket ground. A new system of regulation is required to reduce this unacceptable level of exposure. Such a system needs to incorporate several principles to ensure its success: regulation of energy-dense food and alcohol advertising should be legislated, not voluntary; controls should cover all forms of promotion, not simply direct advertising; there should be scope to address new and emerging forms of promotion; the codes should be drawn up with advice from experts in health and marketing; there should be a capacity for speedy response and action if complaints are upheld; penalties for offending marketers should be sufficient to act as disincentives.

\section{Contributions by the authors}

MD conceived the idea of analyzing the cricket events and contributed to the draft, DG undertook the analysis and JS drafted the paper. All authors participated in progressing the draft to the final version. 


\section{Acknowledgements}

The authors would like to acknowledge the assistance of Janine Wright in analysing the data and to the reviewers for their constructive comments and suggestions .

\section{References}

1. Swinburn B, Egger G, Raza F. Dissecting obesogenic environments: the development and application of a framework for identifying and prioritizing environmental interventions for obesity. Preventive Medicine. 1999;29:563-70.

2. Kelly B, Smith B, King L, Flood V et al. Television food advertising to children: the extent and nature of exposure. Public Health Nutrition. 2007;10(11): 1234-1240.

3. Carroll TE, Donovan RJ. Alcohol marketing in the internet: new challenges for harm reduction. Drug and Alcohol Review. 2002;21:83-91.

4. WHO.int [homepage on the Internet]. Geneva: World Health Organisation [cited 2009 Mar 23]. The extent, nature and effects of food promotion to children: a review of the evidence. Technical paper. Available from: http://www.who.int/dietphysicalactivity/publications/Hastings_paper_marketing.pdf

5. Wiecha JL. Peterson KE, Ludwig DS, Kim J, Sobol A, Gortmaker SL. When children eat what they watch. Impact of television viewing on dietary intake in youth. Arch Pediatr Adolesc Med. 2006;160:436-442.

6. Coalition on Food Advertising to Children [homepage on the Internet]. NSW: Cancer Council 2008 [cited 2009 Mar 23]. Children's health or corporate wealth? Jan 2007 ( $2^{\text {nd }}$ ed). Available from: http://www.cfac.net.au/downloads/briefing_paper

7. Australian Medical Association [homepage on the Internet]. ACT: Australian Medical Association Ltd. 1995-2009 [cited 2009 Mar 23]. Food Labels, Junk Food Ad Bans To Help Australia Slim Down 20/6/2008. Available from: http://www.ama.com.au/node/3328MA

8. Parliament of Australia [homepage on the Internet]. Canberra: Commonwealth of Australia. 2006 [cited 2009 Apr 1]. Debate on Customs Tariff Amendment Bill 2009 and Excise Tariff Amendment Bill 2009. Available from: http://www.aph.gov.au/hansard/senate/dailys/ds160309.pdf

9. Collin J, MacKenzie R. The World Cup, sports sponsorship, and health. The Lancet; 2006:9527:1964-5.

10. Colagiui S, Caterson I. KFC sponsorship of cricket. MJA 2008;189(7):415-6.

11. Lardinoit T, Quester P. Attitudinal effects of combined sponsorship and sponsor's prominence on basketball in Europe. Journal of Advertising Res. 2001; 48-58.

12. Dolphin RR. Sponsorship: perspectives on its strategic role. Corporate Communications: An International Journal. 2003;8(3):173-86

13. Holman C, Donavan R, Corti B, Jalleh G, Frizzell S, Carroll AM. Banning tobacco sponsorship: replacing tobacco with health messages and creating health-promoting environments. Tobacco Control. 1997;6:115-121.

14. Cricket Australia [homepage on the Internet]. Jolimont: Cricket Australia [cited 2009 Mar 23]. Available from: http://www.cricket.com.au/

15. NRL [homepage on the Internet]. National Rugby League. [cited 2009 Mar 23]

Available from: http://www.nrl.com/ 
16. AFL [homepage on the Intenet]. Australian Football League. [cited 2009 Mar 3]. Available from: http://www.afl.com.au/

17. Crisp BR, Swerissen H. Critical processes for creating health-promoting sporting environments in Australia. Health Promot. Int. 2003;18:145-152.

18. Meenaghan T. Sponsorship - legitimising the medium. European Journal of Marketing. 1991;25(11):5-10.

19. iof-org [homepage on the Internet]. London: International Association for the Study of Obesity. [cited 2009 Mar 23]. Sydney Principles. Available from: http://www.iotf.org/sydneyprinciples/documents/sydneyprinciplesfinal_000.pdf

20. Maher A, Wilson N, Signal L, Thomson G. Patterns of sport sponsorship by gambling, alcohol and food companies. BMC Public Health [serial on the Internet].

2006 June [cited 2008 June 3];6:95. Available from: http://www.biomedcentral.com/bmcpublichealth/archive

21. Mennagham, T. Understanding sponsorship effects. Psychology \& Marketing. 2001;18(2):95-98.

22. Connor SM. Food-related advertising on preschool television: building brand recognition in young viewers. Pediatrics. 2006;118(5):1478-1485.

23. Klein N. No Logo. London: Harper Perennial; 2005.

24. OzTAM.com [homepage on the Internet]. North Sydney: Australian Television Audience Measurement. OzTAM Top 20 programs - ranking report (E). [cited 2009 Mar 24]. Available from: http://www.oztam.com.au/html/.

25. Cricket Australia [homepage on the Internet]. Jolimont: Cricket Australia. [cited 2009 Mar 5]. Twenty20 Cricket series. Available from: http://www.cricket.com.au/default.aspx?s=kfctwenty20bigbash0708

26. Lion Nathan [homepage on the Internet]. Sydney: Lion Nathan Ltd 2006 [cited 2009 Mar 24]. XXXX GGOLD Beach Cricket. Available from: http://www.lion-nathan.com.au/Files/Media-Releases/Australian-

BrandReleases/2007/XXXX\%20GOLD\%20BC\%20LAUNCH\%20MEDIA\%20RELEASE_Natio nal.pdf

27. Bradshaw A, McDonagh P, Marshall D. No Space - new blood and the production of brand culture colonies. Journal of Marketing Management. 2006;22:579-599.

28. Formon J, Halford JCG, Summe H, MacDougall M, Keller KL. Food branding influences ad libitum intake differently in children depending on weight status. Appetite. 2009;53:76-83.

29. Harvey B. Measuring the effects of sponsorship. Journal of Advertising Research. 2001; Jan-Feb 59-65.

30. acma.gov [homepage on the Internet]. Canberra: Australian Communications and Media Authority. [cited 2009 Apr 1]. Children's television standards review. Available from: http://www.acma.gov.au/WEB/STANDARD/pc=PC_310262

31. adstandards.gov [homepage on the Internet]. Canberra: Advertising Standards Bureau. [cited 2009 Apr 1]. Available from: http://www.adstandards.com.au/pages/index.asp

32. Lobstein T, Davies S. Defining and labeling "healthy" and "unhealthy” food. Public Health Nutrition. 2008; doi.10.1017/S13689800080002541 pages 1-10

33. dao.health.wa.gov.au [homepage on the Internet]. Mt Lawley: Drug \& Alcohol Office. [cited 2008 Aug 11]. ASSAD Alcohol Report 2005. Available from: 
http://www.dao.health.wa.gov.au/Publications/tabid/99/Default.aspx

34. Atkin C. Effects of televised alcohol messages on teenage drinking patterns. $J$ Adolesc Health Care. 1990;11:10-24.

35. Jones SC, Donovan RJ. Self-regulation of alcohol advertising: Is it working for Australia? Journal of Public Affairs. 2002:2(3):153-165.

36. Donovan K, Donovan R, Howat P, Weller N. Magazine alcohol advertising compliance with the Australian Alcoholic Beverages Advertising Code. Drug and Alcohol Review. 2007;26:73-81. 
Table 2 Sponsor's logo screen time during the game

\begin{tabular}{|l|c|c|c|}
\hline Game & $\begin{array}{l}\text { Game } \\
\text { time } \\
(\mathrm{min})\end{array}$ & $\begin{array}{l}\text { Time sponsor's logo } \\
\text { identifiable } \\
(\mathrm{min})\end{array}$ & $\begin{array}{l}\text { Longest time sponsor's logo on } \\
\text { screen (various forms) } \\
(\mathrm{sec})\end{array}$ \\
\hline $\begin{array}{l}\text { KFC }^{\circledR} \text { Twenty20 } \\
\text { Big Bash }\end{array}$ & 95.8 & $58.5(61 \%)$ & 75 \\
\hline $\begin{array}{l}\text { XXXX }{ }^{T M} \text { GOLD } \\
\text { Beach Cricket }\end{array}$ & 54.0 & $40.0(74 \%)$ & 71 \\
\hline $\begin{array}{l}\text { KFC }^{\circledR} \text { Twenty20 } \\
\text { International }\end{array}$ & 100.5 & $44.5(44 \%)$ & 38 \\
\hline
\end{tabular}

Table 3 Paid advertisement breaks

\begin{tabular}{|l|c|c|c|}
\hline Game & $\begin{array}{c}\text { Telecast time } \\
(\mathrm{min})\end{array}$ & $\begin{array}{c}\text { Paid advertising } \\
(\mathrm{min})\end{array}$ & $\begin{array}{c}\text { Sponsor advertising } \\
(\mathrm{min})\end{array}$ \\
\hline KFC $^{\circledR}$ Twenty20 Big Bash & 98.5 & $2.8(3 \%)$ & 0 \\
\hline $\begin{array}{l}\text { XXXX } \\
\text { Cricket }\end{array}$ & 67.0 & $13.5(20 \%)$ & $3.5(26 \%)$ \\
\hline $\begin{array}{l}\text { KFC }{ }^{\circledR} \text { Twenty20 } \\
\text { International }\end{array}$ & 173.0 & $27.5(16 \%)$ & $2.0(7 \%)$ \\
\hline
\end{tabular}

